\title{
Article \\ Impact and Return on Investment of the Take Kare Safe Space Program-A Harm Reduction Strategy Implemented in Sydney, Australia
}

\author{
Christopher M. Doran ${ }^{1, *(\mathbb{D}}$, Phillip Wadds ${ }^{2}$, Anthony Shakeshaft ${ }^{3} \mathbb{D}$ and Dam Anh Tran ${ }^{3}$ \\ 1 Cluster for Resilience and Well-Being, Centre for Indigenous Health and Equity Research, \\ Central Queensland University, Level 4, 160 Ann Street, Brisbane, QLD 4000, Australia \\ 2 School of Social Sciences, University of New South Wales, Randwick, NSW 2052, Australia; \\ p.wadds@unsw.edu.au \\ 3 National Drug and Alcohol Research Centre, University of New South Wales, \\ Randwick, NSW 2052, Australia; a.shakeshaft@unsw.edu.au (A.S.); dam.tran@unsw.edu.au (D.A.T.) \\ * Correspondence: c.doran@cqu.edu.au; Tel.: +61-412-935-084
}

Citation: Doran, C.M.; Wadds, P.; Shakeshaft, A.; Tran, D.A. Impact and Return on Investment of the Take Kare Safe Space Program-A Harm Reduction Strategy Implemented in Sydney, Australia. Int. J. Environ. Res. Public Health 2021, 18, 12111. https:// doi.org/10.3390/ijerph182212111

Academic Editor: Paul B. Tchounwou

Received: 27 October 2021

Accepted: 17 November 2021

Published: 18 November 2021

Publisher's Note: MDPI stays neutral with regard to jurisdictional claims in published maps and institutional affiliations.

Copyright: (c) 2021 by the authors. Licensee MDPI, Basel, Switzerland. This article is an open access article distributed under the terms and conditions of the Creative Commons Attribution (CC BY) license (https:// creativecommons.org/licenses/by/ $4.0 /)$.

\begin{abstract}
Safe spaces are increasingly utilized to reduce alcohol-related harm, violence, crime and improve public safety in nightlife settings. This study aimed to determine the impact and return on investment of the Take Kare Safe Space (TKSS) program-a harm reduction program implemented to address alcohol-related violence and disorder in three locations in Sydney's nighttime economy between 2014 and 2019. TKSS ambassadors provided support at static safe spaces and patrolled designated nightlife precincts to provide practical assistance to vulnerable and intoxicated people. Ambassadors recorded information relating to these interactions including 'client' age, gender, perceived level of intoxication, time and length of engagement with the program. Costs of program implementation and benefits of major incidents averted were obtained to allow calculation of return on investment. From December 2014 to April 2019, 66,455 people were supported by TKSS ambassadors. Most users were male (62\%) and aged 18-25 years (66\%). Of 3633 interventions by ambassadors, serious risk of harm was averted in 735 cases $(20 \%)$. The program's return on investment is estimated at 2.67, suggesting that a $\$ 1$ investment results in $\$ 2.67$ in benefits. Safe Spaces are extensively utilized, particularly by young males with high levels of intoxication, and represent a positive return on investment. Despite the growth of such services, there remains a notable absence of rigorous, independent evaluation regarding the outcomes and/or social benefit of safe space programs. From a policy perspective, there is a need for more high-quality economic evaluations to better inform decisions about competing uses of limited resources.
\end{abstract}

Keywords: harm reduction; cost-benefit analysis; return on investment; crime; violence; alcohol

\section{Introduction}

Alcohol use has a significant negative social and public health impact [1]. In Australia, alcohol is the sixth highest risk factor contributing to the burden of disease in Australia [2] and was responsible for $4.5 \%$ of the total burden of disease and injury in 2015 [2]. The impacts of alcohol misuse, either alone or in combination with other illicit substances, can be serious and far reaching. Short- and long-term harms include traffic accidents, injuries, aggressive and anti-social behaviour, physical and sexual violence, increased risk of chronic disease and cancer, and premature mortality [3-5]. These harms, to both the drinker and others, often play out in sites of night-leisure where high-risk alcohol consumption often occurs [6]. In Australia, data suggest that alcohol is a contributing factor in approximately half of all non-domestic assaults that occur between $6 \mathrm{pm}$ and midnight [7], and 34\% of all road fatalities [8]. Alcohol misuse has significant flow-on effects, consuming community, law enforcement and health resources and costing the Australian economy an estimated $\$ 14$ billion dollars per year [9]. 
In Australia, night-time alcohol-related violence and disorder have been a significant community concern over the last decade, with numerous high-profile deaths linked with heavy alcohol and other drug use [10]. In response to increasing concerns about public safety in late-night trading areas, the Liquor Amendment Act (LAA) [11] was introduced into law in 2014 in New South Wales (NSW), Australia's most populous state. The LAA included a range of policy interventions regulating nightlife in defined precincts of NSW, including restrictions on entry and re-entry to venues after 1:30 am (a "lock out" or one-way door policy) and cessation of the service of alcohol from 3:00 am for all licensed premises within the designated area. Other restrictions included a liquor license freeze preventing new venue licenses in the newly established central business district precinct, increased powers for police, restriction on takeaway alcohol sales from $10 \mathrm{pm}$ and harsher sentencing for alcohol-related violence [12]. Alongside the implementation of the LAA, a night-time safe space program designed to support vulnerable patrons was established in three key nightlife areas in Sydney's inner city, with the aim of reducing alcohol-related harm, violence and crime. This program, the Take Kare Safe Space (TKSS) program, was a key initiative of the plan of management for the Sydney central business district entertainment precinct.

For the purposes of this paper, 'safe space' refers to a harm reduction service often run in partnership with health, community, emergency or welfare services to increase public safety and amenity in town centers or other public spaces [13]. Night-time safe spaces have been in operation for several years in many parts of world to reduce the impact of alcohol-related harm, including at music festivals, major events, and in nightlife precincts. Typically, night-time safe spaces provide a combination of medical assessment, first aid, counselling or support, hydration, supervised recovery, and/or practical supports such as the provision of food and directions. In the United Kingdom, a recent study estimated there are up to 45 safe spaces in operation across the country [13]. In Australia, several similar services operate [14-16]. The TKSS program was implemented in Sydney in 2014 and was designed to reduce alcohol-related harms, violence and reduce the risk of crime by providing a place where vulnerable young people could access safety and support. Its operations are supported by small teams of paid and volunteer ambassadors who patrol designated precincts to provide alcohol-affected and other vulnerable people in unsafe situations with practical on-the-spot assistance. These teams also manage static safe spaces, providing a place to rest, receive first aid and hydration, charge mobile phones, find transport home, and wait for friends or family. The program is well integrated with other critical safety and health services, including venue security staff, local close circuittelevision control rooms, and emergency services including NSW Ambulance and NSW Police, and is a key point of contact for licensed venues dealing with or ejecting heavily intoxicated patrons.

Despite the increasing use of safe spaces as part of local government and community responses to addressing alcohol-related violence, there remains a notable absence of rigorous, independent evaluation of the effectiveness of programs in achieving benefits [17]. To date, only two pilot studies have examined the economic benefit of safe spaces $[18,19]$. Another study has presented case studies of operation [20], with a third, ongoing, project examining the impact of safe night precincts on a wide range of health and justice outcome measures [21]. Other studies evaluating 'like' interventions, including shelter and van programs [16], have shown limited effectiveness on reducing alcohol-related harm and violence, despite high community value and patron use. Similarly, there have been a range of studies into programs and interventions that feature key components of the TKSS service delivery model, including connection with CCTV control rooms and the establishment of radio communication with emergency services and security teams [22,23], but not the full range of their interventions and services. The variance in safe space services makes meaningful comparison of the benefit of programs difficult and highlights the ongoing need for rigorous evaluation of such programs. 
Accordingly, this study aimed to determine the impact and return of investment of the TKSS program implemented in Sydney, Australia, as part of a city-wide plan to address alcohol-related violence and disorder.

\section{Material and Methods}

Design. The methodology underpinning the evaluation was guided by the NSW Government's Program Evaluation Guidelines to examine process, outcome and economic indicators [24]. The evaluation relies on internal program-level data collected by the TKSS ambassadors and qualitative data collected from clients and stakeholders. A mixed-methods approach was embedded into the evaluation framework combining both qualitative and quantitative methods. Process indicators assess uptake of the program; client characteristics including age, gender and intoxication levels; time and duration of contact; services and/or referrals provided. Outcome indicators assess ambassador intervention that seek to prevent harm; and, reductions in demand for acute services (e.g., police incidents, ambulatory care and emergency department (ED) presentations). Economic indicators enable an assessment of whether the economic benefits of the TKSS program outweigh its costs. The time frame of the evaluation spans the period December 2014-April 2019 (inclusive).

TKSS program. The TKSS program commenced operations in Town Hall in the central business district of Sydney, Australia, in December 2014. A second site in Kings Cross commenced operations in July 2015 and a third site at Darling Harbor commenced operation in February 2017. All three sites are in or near the central business district entertainment precinct of Sydney and are renowned for their nightlife. TKSS operated year-round from $10 \mathrm{pm}$ to 4 am on Friday and Saturday nights. Each site of the TKSS program is staffed by groups of 3-4 team members, called ambassadors, including a paid team leader and volunteers. Volunteers are drawn from the public and student recruitment pathways from established relationships between the program and local universities. Volunteer training is provided by the program, and includes instruction on basic first aid, the provision of care for, and communication with, intoxicated patrons, de-escalation and other program safety protocols. Alongside public safety interventions in situations of "risk" (including high-level intoxication and conflict), the TKSS program provides first aid support, escort to accommodation, assistance with accessing transport, a phone charging station, help connecting with friends or family, and general assistance with directions and local information. When the support required exceeds the program's scope and capacity, ambassadors refer incidents to appropriate emergency or other social services. Integral to the TKSS program is its connection to, and interaction with, other agencies and nightlife service providers to ensure the most appropriate care is provided for those in need of assistance. This includes collaboration with City Rangers, licensed premises, venue security, police, closed circuit-television operators, and transport staff.

As part of program delivery, ambassadors record a range of information relating to client interactions with TKSS, either on a paper-based form or via a mobile phone application. Data recorded included age and gender of the service user, the time support was provided, the length of time each user was in contact with the service, and the perceived level of intoxication of the person/people receiving support (based on the NSW Responsible Service of Alcohol intoxication guidelines [25]). The types of support provided to people receiving assistance is also recorded, including spending time at the Safe Space, Ambassador intervention to de-escalate or avert serious risk of harm, request for directions, phone charging, and receipt of first aid.

Return on investment. Costs were determined by combining information on TKSS operating costs with the value of volunteer time implementing the program. The value of one hour of volunteer time was calculated using Australian Bureau of Statistics data on average weekly earnings and adjusting for a $35 \mathrm{~h}$ working week [26]. Benefit was defined as major incidents averted because of ambassador interventions, combined with willingness to pay estimates of the social (community) value attached to averted major road traffic injuries. Given it is uncertain whether an assault, theft or injury would have occurred if the 
intervention did not happen, ambassadors used their understanding and experience in the city at night to identify those incidents that were of serious risk of occurring.

Table 1 provides an overview of all the interventions provided by Take Kare ambassadors and the subset of those interventions that the ambassadors classified as being at serious risk of occurring. For theft, the category "passed out-valuables visible" is included. For risk of injury, only road-related traffic injuries are considered with a further assumption made that only a fraction of these injuries would be classified as major (derived using the average of major assaults and sexual assaults averted). Over the period December 2014-April 2019 (inclusive), ambassadors' interventions averted an estimated 735 incidents that were of serious risk of occurring, out of a total of 3633 interventions.

Table 1. Interventions that averted serious risk of harm (December 2014-April 2019).

\begin{tabular}{|c|c|c|c|}
\hline Intervention & $\begin{array}{l}\text { Ambassador Interventions } \\
\text { (14 December-19 April) }\end{array}$ & $\begin{array}{l}\text { Serious Risk of } \\
\text { Harm Averted }\end{array}$ & $\begin{array}{l}\text { Proportion of } \\
\text { Interventions }\end{array}$ \\
\hline Risk of assault minimized & 1357 & 235 & $17 \%$ \\
\hline Risk of sexual assault minimized & 664 & 50 & $8 \%$ \\
\hline Risk of theft minimized & 904 & 362 & $40 \%$ \\
\hline $\begin{array}{l}\text { Risk of road traffic accidents } \\
\text { minimized }\end{array}$ & 708 & 88 & $12 \%$ \\
\hline Total & 3633 & 735 & $20 \%$ \\
\hline
\end{tabular}

Costs of major incidents averted were derived using estimates of incidents averted together with a cost estimate for each incident. The cost of assault and sexual assault (reported crime) was valued using estimates derived by Byrne et al. (2012) [27]. The cost of theft (reported crime) was valued using estimates by the Australian Institute of Criminology [28]. The cost of a road traffic injury was valued using estimates from the Bureau of Infrastructure, Transport and Regional Economics [29]. All estimates were adjusted to 2018 dollars using consumer price index information from the Australian Bureau of Statistics [30]. Cost per assault was estimated at $\$ 18,933$; cost per sexual assault at $\$ 30,495$; cost per theft at $\$ 434$; and cost per road traffic injury at $\$ 5745$. A willingness to pay approach was used to estimate the social (community) value of the program [31]. This approach estimates the social cost of death or injury by establishing how much society is willing to pay to reduce the risk (or avoid) fatality or serious injury. This method is preferred to other traditional approaches, such as a human capital approach, as it provides a more representative value of costs to individuals as it takes into consideration other general wellbeing factors, not just earnings and productivity. The value of a statistical life year saved is estimated as $\$ 196,484$ (in 2018 dollars) and represents the value that society places on preventing one premature death each year [32].

The outcome of the return on investment is reported as a ratio (benefits/costs). Two additional sensitivity analyses were conducted to explore the robustness of results to changes in assumptions. Sensitivity analysis 1 examines changes in the attribution of serious risk of injury diverted from $100 \%$ (baseline) to $75 \%$. Sensitivity analysis 2 examines the benefit cost ratio for the year 2016-2017 when the TKSS program was fully operational in three sites-Town Hall, Kings Cross and Darling Harbour.

\section{Results}

User profile. Cumulatively, from December 2014 to April 2019 (inclusive), 66,455 people were supported by the TKSS program. Figure 1 provides an overview of TKSS users by age and gender for those where details were recorded $(n=41,395)$. Sixty-two percent $(n=25,460)$ of users were males and $38 \%(n=15,859)$ were female. The largest proportion of service users were aged $18-25$ years, accounting for $66 \%(n=27,279)$ of the sample, followed by those aged 26-39 ( $n=7808$ or 19\%). Of the 8872 assessments completed to determine level of intoxication, $46 \%(n=4061)$ were perceived to have had a high level of 
intoxication, 36\% ( $n=3190)$ a mild level of intoxication, $11 \%(n=955)$ were perceived as sober and $8 \%(n=666)$ were perceived to be under the influence of drugs.

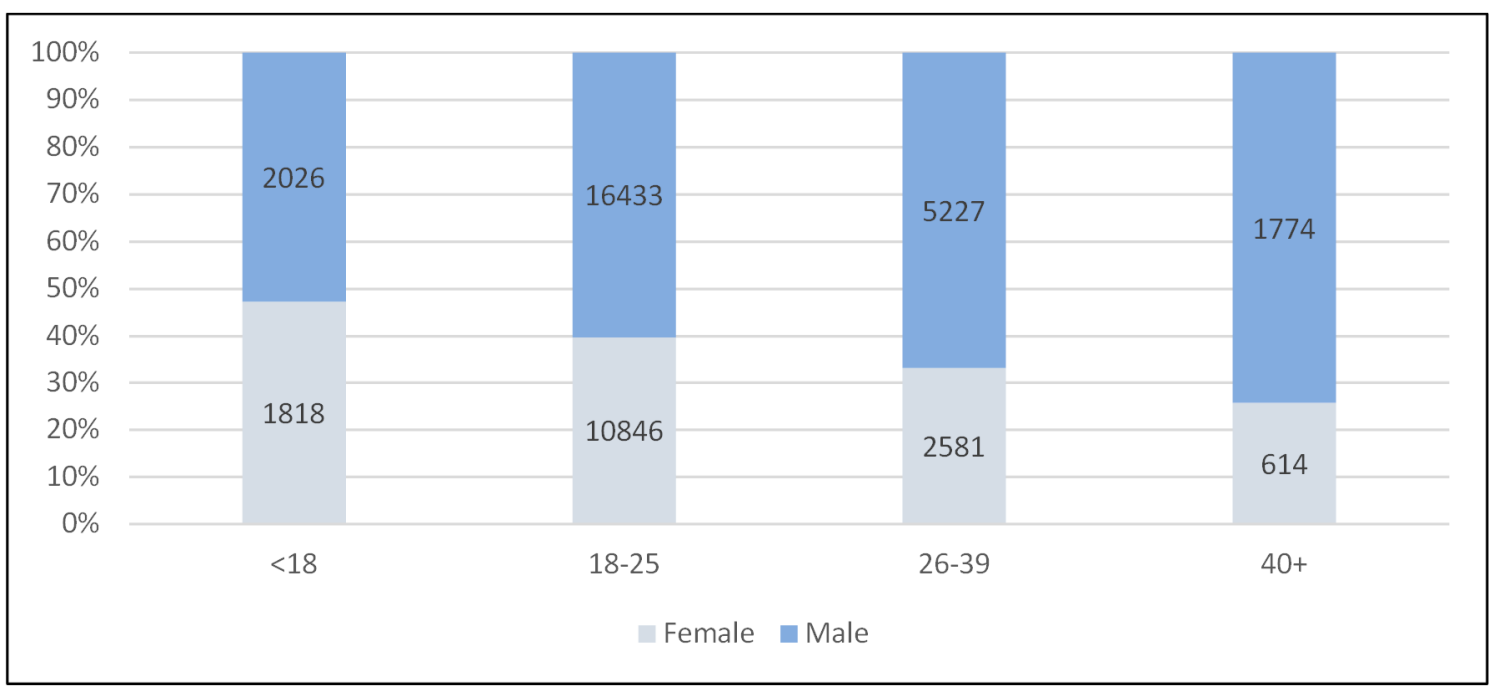

Figure 1. Service users by age and gender.

Service Use. Sixty-nine percent of all contacts $(n=5356)$ occurred between the hours of $11 \mathrm{pm}$ and $2 \mathrm{am}$. Seventy percent $(n=5392)$ of users were in contact with the service for between 1 and $20 \mathrm{~min}, 17 \%(n=1360)$ for between 21 and $60 \mathrm{~min}$ and 13\% $(n=981)$ for greater than one hour. Most users $(66 \%$ or $n=41,396)$ spent time at the Safe Space, $19 \%$ $(n=12,645)$ were supported in other ways (defined as incidents) and $18.7 \%(n=12,414)$ requested directions, primarily related to transport.

TKSS program benefits. While it is uncertain whether an assault, theft or injury would have occurred if the intervention did not happen, ambassadors use their judgement based on their understanding and exposure to patterns of behaviour in the city at night. For theft, the category "passed out-valuables visible" is included. For risk of injury, only road-related traffic injuries are considered with a further assumption made that only a fraction of these injuries would be classified as major (derived using the average of major assaults and sexual assaults averted). Table 1 provides an overview of total interventions by ambassadors and those perceived to have de-escalated or averted serious risk of harm. Over the period December 2014-April 2019, serious risk of harm was averted in 735 cases from a total of 3633 interventions.

Return on investment. Table 2 provides an overview of total estimated costs and benefits of the TKSS program over the period December 2014 April 2019. TKSS operating costs were estimated at $\$ 2,792,349$, including program costs of $\$ 1983,198$ and the market value of volunteer time at $\$ 809,152$. Total benefit in terms of costs averted and community value were estimated at $\$ 7,461,810$. The return on investment is estimated at 2.67 , suggesting that a $\$ 1$ investment results in $\$ 2.67$ in benefits. The return on investment ratio ranges from a low of 2.00 with a $75 \%$ attribution rate to a high of 3.83 when the TKSS was fully operational (i.e., 2016-2017) at three sites. This suggests a range of benefits for every $\$ 1$ invested of between $\$ 2.00$ and $\$ 3.83$. 
Table 2. Return on investment of TKSS program December 2014-April 2019 (inclusive).

\begin{tabular}{cccc}
\hline & Baseline & $\begin{array}{c}\text { Sensitivity Analysis 1 } \\
\text { (75\% Attribution) }\end{array}$ & $\begin{array}{c}\text { Sensitivity Analysis 2 } \\
\text { (Fully Operational TKSS) }\end{array}$ \\
\hline Cost & & & \\
Cost of TKSS program & $\$ 1,983,198$ & $\$ 1,983,198$ & $\$ 470,687$ \\
Cost of volunteer time & $\$ 809,152$ & $\$ 809,152$ & $\$ 189,168$ \\
Total cost & $\$ 2,792,349$ & $\$ 2,792,349$ & $\$, 855$ \\
Benefits & & $\$ 4,977,295$ & $\$ 2,211,956$ \\
Cost averted & $\$ 6,636,393$ & $\$ 619,063$ & $\$ 317,666$ \\
Community value & $\$ 825,417$ & $\$ 5,596,358$ & $\$ 2,529,621$ \\
Total benefit & $\$ 7,461,810$ & $\$ 2,804,008$ & 2.00 \\
\hline Total benefit-total costs & $\$ 4,669,461$ & $31,869,766$ \\
Return on investment & 2.67 & 3.83 \\
\hline
\end{tabular}

\section{Discussion}

The purpose of the current study was to determine the impact and return on investment of the TKSS, a harm reduction program embedded within the community to address alcohol-related violence and disorder in the night-time economy. The evaluation relied on an existing framework endorsed by the NSW Government to examine process, outcome and economic indicators [24]. Using a range of data sources, the results of the evaluation demonstrate that the Safe Spaces were extensively utilized, averted harm and resulted in a positive economic investment. These findings are consistent with evaluations of other types of Safe Spaces $[13,15,33,34]$.

The results indicate that the Sydney Safe Spaces were well represented by young men with high levels of intoxication. This is also consistent with global estimates of alcohol use that show higher rates of alcohol use among young men compared to women [35]. Young men are also a group that evidence has consistently show are at high risk of being both perpetrators and victims of alcohol-related violence and harm [36-38], and vulnerable to negative biological, neurological, social and psychological effects of alcohol [35].

The Take Kare Safe Space aimed to improve public safety and reduce alcohol-related harm and violence by providing a place where vulnerable people could access support in the weekend nighttime economy. One of the objectives of the evaluation was to examine the return on investment. Edmunds et al. (2018) conducted a systematic review of economic evaluations of interventions for high risk young people [39]. Although not specifically focused on Safe Spaces, the authors report a lack of good-quality empirical evidence related to interventions for at risk youth [39]. Their findings were consistent with another review conducted by Knight et al. (2017) that examined the quality and effectiveness of interventions that target multiple risk factors among young people [40] Knight et al. (2017) suggested that more methodologically rigorous evaluations of interventions targeting multiple risk factors among high-risk young people are required, especially for those delivered in community settings [40].

Further, there is a lack of evidence pertaining to community preferences for such interventions. Attaching a value to community benefit is seen as a valuable input in economic evaluations that adopt a social perspective [41]. A recent study by Edmunds et al. (2021) used discrete choice experiments to explore community value and preferences for reducing youth crime and improving community safety using BackTrack [42]. The BackTrack program is a multicomponent community intervention targeting 14-17-year-old high risk young people [42-44]. The authors found a strong community preference for youth based programs such as BackTrack that are community based rather than traditional means of dealing with youth crime through punitive measures [42].

The current research estimated a return on investment at 2.67, suggesting that every $\$ 1$ invested in TKSS resulted in $\$ 2.67$ in benefits. This return on investment is conservative, as the analysis did not quantify the full spectrum of potential benefits associated with the 
TKSS program or the value of community benefit. For example, only $20 \%(n=735)$ of all interventions made by ambassadors that averted serious risk of harm were included in the formal return on investment analysis out of 3633 actual interventions. Other likely benefits of the program that are difficult to quantify such as improvements in public safety and amenity, more efficient resource allocation for service providers, improved partnership, communication and resourcing, and flow-on effects for tourism and investment, suggest the true return on investment is likely to be much higher. Indeed, the three-month pilot evaluation of the TKSS program estimated a positive return of $\$ 9$ for every $\$ 1$ invested, largely due to savings attributed to the cost of police, ambulance and additional medical services [18]. A return on investment analysis of pilot Safe Space initiative in the United Kingdom indicates that for every $£ 1$ invested, benefits exceed $£ 1.80$ [19]. The authors of the United Kingdom pilot suggest that it is likely that a permanent Safe Space facility has the potential to offer even better value for money, as strong branding and sustained publicity will integrate it into the local night-time economy and lead to higher usage [19].

The positive return on investment of the Sydney TKSS is supported by a statistical analysis of routinely collected datasets that showed consistency in the pattern of declining alcohol-related assaults, alcohol-related emergency department presentations and alcoholrelated ambulance dispatches within the geographical boundaries of TKSS sites (data not shown but available upon request) since 2009. Although the trends pre- and postimplementation of the LLA and the TKSS program were not significant, the downward trend suggests that Safe Spaces may have had a dampening effect on emergency department presentations and ambulance dispatches (i.e., they keep the demand for ED and ambulance services constant) but not the occurrence of assaults. This would be consistent with previous research on community-based responses to alcohol harms, which showed that alcohol harms can be less in communities with community action responses (compared to communities who do not have those responses), but sustaining reductions in alcohol harms over time is likely to need more targeted and restrictive legislation to control the availability of alcohol, especially at high-risk times [45].

Strengths and limitations. This evaluation should be interpreted with reference to the following strengths and limitations. A limitation of the evaluation is the use of internal data collected by Safe Space ambassadors to estimate impacts on alcohol harms. These data were self-reported and collected using an unvalidated tool that may have been prone to recall or reporting bias. Second, during the period of this study (December 2014-April 2019), funding to operate TKSS was sporadic. This sporadic funding impacted on operational capacity to the extent that the Kings Cross Safe Space was closed on Friday nights, operating only on Saturday night. Third, the responsibilities of operating the Safe Spaces transitioned from an external organisation, St John Ambulance, to another organisation-Stay Kind. This transition resulted in additional financial burdens associated with operating the TKSS program. Previously Stay Kind operated from offices provided pro bono with one paid staff member. Bringing the program inhouse required establishing a range of additional systems and processes for running the program including directly employing the team leaders, inhouse management of staff, training and induction of volunteers as well as leasing an office and acquiring vehicles within the constraints of reduced and sporadic funding. Fourth, for the duration of this study, the City of Sydney Central Business District underwent significant capital works that impacted on the mobility of ambassadors and capacity to operate efficiently. This may have also impacted on the number of users to the service. Despite these challenges, the TKSS program has met it objective to provide a harm reduction service where vulnerable young people can access support and a safe place or a safe passage home. A real strength of the program is the ambassadors collection of real-time data. The impacts on alcohol harms are usually not accurately recorded, or captured at all, because they do not come to the attention of relevant authorities [46], or are not captured as part of routine data collection [47]. Ambassadors also demonstrated a willingness to engage with predominantly intoxicated youth and various night time economy participants. Such engagement could also be perceived as a conduit that enabled 
better partnerships, communication and a more complete suite of resources to manage Sydney nightlife thereby keeping both vulnerable youth and the general public safe. There are likely to be significant flow-on effects of a safer night time environment for tourism and investment.

\section{Conclusions}

Safe Spaces are extensively utilized, particularly by young males with high levels of intoxication, and represent a positive return on investment. Harm reduction programs such as TKSS play a key role in de-escalating conflict and averting the risk of serious harm. Safe Spaces offer a positive return on investment and should play a key role in any city-wide management plan to address alcohol-related violence and disorder in the night-time economy. However, despite the growth of such services, there remains a notable absence of rigorous, independent evaluation regarding the outcomes and/or social benefit of safe space programs. From a policy perspective, there is a need for more high-quality economic evaluations to better inform decisions about competing uses of limited resources.

Author Contributions: C.M.D. contributed to conceptualization, administration, methods, data, analysis, writing of the original draft and review and editing. P.W. contributed to conceptualization, administration, methods, data, analysis, writing, reviewing, and editing. A.S. contributed to conceptualization, funding acquisition, administration, methods, data, analysis, writing, reviewing, and editing. D.A.T. contributed to analysis, writing, reviewing, and editing. All authors have read and agreed to the published version of the manuscript.

Funding: This research was funded by the NSW Government Department of Justice. The funder had no role in study design, the collection, analysis, and interpretation of data, writing this paper or the decision to submit this article for publication.

Institutional Review Board Statement: This study was conducted according to the guidelines of the Declaration of Helsinki. Ethics approval was provided by the University of New South Wales Ethics Committee (HC17509). The research was performed in compliance with relevant laws and institutional guidelines.

Informed Consent Statement: No data collected from participants.

Data Availability Statement: The datasets generated and analysed during the current study are available from the corresponding author on reasonable request, and subject to approval.

Acknowledgments: The authors would like to thank members of the Take Kare Safe Space Evaluation Advisory Group for their contribution to the project.

Conflicts of Interest: All authors declare no conflict of interest.

\section{References}

1. World Health Organization. Global Status Report on Alcohol and Health 2018; World Health Organization: Geneva, Switzerland, 2018; Available online: https:/ /apps.who.int/iris/handle/10665/274603 (accessed on 27 October 2021).

2. Australian Insitite of Health and Welfare. Alcohol, Tobacco and Other Drugs in Australia; Australian Institute of Health and Welfare: Canberra, Australia, 2020; Cat. no: PHE 221. Available online: https:/ /www.aihw.gov.au/reprts/alcohol/alcohol-tobacco-otherdrugs-australia/contents/about (accessed on 27 October 2021).

3. Taylor, B.; Irving, H.M.; Kanteres, F.; Room, R.; Borges, G.; Cherpitel, C.; Greenfield, T.; Rehm, J. The more you drink, the harder you fall: A systematic review and meta-analysis of how acute alcohol consumption and injury or collision risk increase together. Drug Alcohol Depend. 2010, 110, 108-116. [CrossRef] [PubMed]

4. Boffetta, P.; Hashibe, M. Alcohol and cancer. Lancet Oncol. 2006, 7, 149-156. [CrossRef]

5. Australian Institute of Health and Welfare. National Drug Strategy Household Survey 2016: Detailed Findings; Australian Institute of Health and Welfare: Canberra, Australia, 2017. Available online: https:/ /www.aihw.gov.au/reports/illicit-use-of-drugs/2016 -ndshs-detailed/summary (accessed on 27 October 2021).

6. Miller, P.; Pennay, A.; Droste, N.; Butle, E.; Jenkinson, R.; Hyder, S.; Quinn, B.; Chikritzhs, T.; Tomsen, S.; Wadds, P.; et al. A comparative study of blood alcohol concentrations in Australian night-time entertainment districts. Drug Alcohol Rev. 2014, 33, 338-345. [CrossRef] [PubMed]

7. New South Wales Bureau of Crime Statistics and Research. Alcohol Related Violence; BOCSAR: Sydney, Australia, 2019. Available online: https:/ / www.bocsar.nsw.gov.au/Pages/bocsar_pages / Alcohol_Related_Violence.aspx (accessed on 27 October 2021). 
8. Bureau of Transport Infrastructure and Regional Economics. Fatal Road Crashes in Australia in the 1990s and 2000s; Information Sheet 41; Bureau of Transport, Infrastructure and Regional Economics: Canberra, Australia, 2011. Available online: https: //www.bitre.gov.au/sites/default/files/is_041.pdf (accessed on 27 October 2021).

9. Manning, M.; Smith, C.; Mazerolle, P. The Societal Costs of Alcohol Misuse in Australia; Trends E Issues in Crime and Criminal Justice No. 454; Australian Institute of Criminology: Canberra, Australia, 2013. Available online: https://www.aic.gov.au/publications/ tandi/tandi454 (accessed on 27 October 2021).

10. Wadds, P. Crime, Policing and (In)Security: Press Depictions of Sydney's Night-Time Economy. Curr. Issues Crim. Justice 2015, 27, 95-112. [CrossRef]

11. NSW Government. Liquor Amendment Act Stat; NSW Government: Sydney, Australia, 2014. Available online: https://legislation. nsw.gov.au/view/pdf/asmade/act-2014-3 (accessed on 27 October 2021).

12. Wadds, P. Policing Nightlife: Security, Transgression and Urban Order; Routledge: Oxon Hill, MD, USA, 2020.

13. MAKE Associates. A Study of 'Safe Spaces' in the UK Night-time Economy; Portman Group: Edinburgh, Scotland, 2017; Available online: https:/ / www.vennture.org.uk/wp-content/uploads/2018/06/Home-Office-Portman-Group-Safe-Spacesreport.pdf (accessed on 27 October 2021).

14. Nightwatch Chaplaincy. Chaplin Warch: Watching out for You. 2021. Available online: https://www.chaplainwatch.org.au/ nightwatch/ (accessed on 27 October 2021).

15. Salvation Army. Youth Street Teams. 2019. Available online: https://salvos.org.au/melbourne614/what-we-offer/youth-streetteams / (accessed on 27 October 2021).

16. Ward, B.M.; O'Sullivan, B.; Buykx, P. Evaluation of a local government "shelter and van" intervention to improve safety and reduce alcohol-related harm. BMC Public Health 2018, 18, 1370. [CrossRef] [PubMed]

17. Miller, P.; Curtis, A.; Chikritzhs, T.; Toumbourou, J.W. Interventions for Reducing Alcohol Supply, Alcohol Demand and Alcohol-Related Harm; National Drug Law Enforcement Research Fund: Canberra, Australia, 2015.

18. City of Sydney. Safe Space and Take Kare Ambassador Pilot Program; City of Sydney: Sydney, Australia, 2015. Available online: https:/ / www.staykind.org/wp-content/uploads/2019/09/TKSS-Interim-Report-Final.pdf (accessed on 27 October 2021).

19. NHS Hastings \& Rother Clinical Commissioning Group. Reducing Alcohol-Related Harm amongst Young People Aged 17-25 Years Old Evaluation Report for the Life Stage 4 Project, Part of the Healthy Hastings and Rother Health Behaviour Change Programme; NHS Hastings \& Rother Clinical Commissioning Group: Bexhill-on-Sea, UK, 2016.

20. Local Government Association. Approaches to Managing the Night-Time Economy; Local Government Association: Sydney, Australia; London, UK, 2019. Available online: https:/ /www.local.gov.uk/sites/default/files/documents/10.40\%20Approaches\%20to\%20 managing\%20the\%20night-time\%20economy\%20-\%20case\%20studies_v04_2.pdf (accessed on 27 October 2021).

21. Miller, P.G.; Ferris, J.; Coomber, K.; Zahnow, R.; Carah, N.; Jiang, J.; Kypri, K.; Chikritzhs, T.; Clough, A.; Livingston, M.; et al. Queensland Alcohol-related violence and Night Time Economy Monitoring project (QUANTEM): A study protocol. BMC Public Health 2017, 17, 789. [CrossRef] [PubMed]

22. Miller, P.; Sønderlund, A.; Coomber, K.; Palmer, D.; Gillham, K.; Tindall, J. Do community interventions targeting licensed venues reduce alcohol-related emergency department presentations? Drug Alcohol Rev. 2011, 30, 546-553. [CrossRef] [PubMed]

23. Curtis, A.; Coomber, K.; Droste, N.; Hyder, S.; Palmer, D.; Miller, P.G. Effectiveness of community-based interventions for reducing alcohol-related harm in two metropolitan and two regional sites in Victoria, Australia. Drug Alcohol Rev. 2017, 36, 359-368. [CrossRef] [PubMed]

24. Department of Premier and Cabinet. NSW Government Program Evaluation Guidelines; NSW Government: Sydney, Australia, 2016. Available online: http://www.dpc.nsw.gov.au/_data/assets/pdf_file/0009/155844/NSW_Government_Program_Evaluation_ Guidelines.pdf (accessed on 27 October 2021).

25. NSW Government. Intoxication Guidelines (GL4003); NSW Government: Sydney, Australia, 2017. Available online: https: //www.liquorandgaming.nsw.gov.au/documents/gl/gl4003-intoxication-guidelines.pdf (accessed on 27 October 2021).

26. Australian Bureau of Statistics. 6302.0 Average Weekly Earnings, Australia; Australian Bureau of Statistics: Canberra, Australia, 2019. Available online: https:/ / www.abs.gov.au/statistics/labour/earnings-and-work-hours/average-weekly-earnings-australia/ may-2019 (accessed on 27 October 2021).

27. Byrnes, J.M.; Doran, C.M.; Shakeshaft, A.P. Cost per incident of alcohol-related crime in New South Wales. Drug Alcohol Rev. 2012, 31, 854-860. [CrossRef] [PubMed]

28. Smith, R.G.; Jorna, P.; Sweeney, J.; Fuller, G. Counting the Costs of Crime in Australia: A 2011 Estimate; Australian Institute of Criminology: Canberra, Australia, 2014.

29. Risbey, T.; Cregan, M.; De Silva, H. Social Cost of Road Crashes; Australasian Transport Research Forum: Canberra, Australia, 2010. Available online: https:/ / www.bitre.gov.au/publications/2010/files/sp_003_Risbey_Cregan_deSilva.pdf (accessed on 27 October 2021).

30. Australian Bureau of Statistics. 6401.0 Consumer Price Index, Australia; Australian Bureau of Statistics: Canberra, Australia, 2019. Available online: https:/ / www.abs.gov.au/statistics/economy/price-indexes-and-inflation/consumer-price-index-australia/ dec-2019 (accessed on 27 October 2021).

31. New South Wales Treasury. Evaluation of the Sydney CBD Entertainment Precinct Plan of Management; NSW Government: Sydney, Australia, 2016. Available online: https://www.treasury.nsw.gov.au/sites/default/files/2017-04/Sydney\%20CBD\%20 Entertainment\%20Precinct\%20Plan\%20of\%20Management.pdf (accessed on 27 October 2021). 
32. Office of Best Practice Regulation. Best Practice Regulation Guidance Note: Value of a Statistical Life; Australian Government: Canberra, Australia, 2014. Available online: https://www.dpmc.gov.au/sites/default/files/publications/Value_of_Statistical_ Life_guidance_note.pdf (accessed on 27 October 2021).

33. NHS Hastings \& Rother Clinical Commissioning Group. Hastings Safe Space 18-Month Project Evaluation; NHS Hastings \& Rother Clinical Commissioning Group: Bexhill-on-Sea, UK, 2019; Available online: https://www.eastsussexccg.nhs.uk/wp-content/ uploads/sites/3/2021/01/Hastings-Safe-Space-Evaluation-Final-Report-September-2019.pdf (accessed on 27 October 2021).

34. Surrey and Borders Partnership. The Safe Haven Aldershot Evaluation Report; National Health Service: Aldershot, UK, 2014; Available online: https:/ / acem.org.au/getmedia/d955dbb0-86c6-4ca2-b25c-ac367b949bb8/Hampshire-Crisis-Cafe-EvaluationReportUK (accessed on 27 October 2021).

35. Lees, B.; Meredith, L.R.; Kirkland, A.E.; Bryant, B.E.; Squeglia, L.M. Effect of alcohol use on the adolescent brain and behavior. Pharmacol. Biochem. Behav. 2020, 192, 172906. [CrossRef] [PubMed]

36. Laslett, A.M.; Catalano, P.; Chikritzhs, T.; Dale, C.; Doran, C.M.; Ferris, J.; Jainullabudeen, T.; Livingston, M.; Matthews, S.; Mugavin, J.; et al. The Range and Magnitude of Alcohol's Harm to Others; AER Centre for Alcohol Policy Research, Turning Point Alcohol and Drug Centre: Fitzroy, Australia, 2010.

37. Lindsay, J. The gendered trouble with alcohol: Young people managing alcohol related violence. Int. J. Drug Policy 2012, 23, 236-241. [CrossRef] [PubMed]

38. Wadds, P.; Fileborn, B.; Tomsen, S. Carnival, Sexual Violence and Harm at Australian Music Festivals. Br. J. Criminol. 2021. [CrossRef]

39. Edmunds, K.; Ling, R.; Shakeshaft, A.; Doran, C.M.; Searles, A. Systematic review of economic evaluations of interventions for high risk young people. BMC Health Serv. Res. 2018, 18, 1-10. [CrossRef] [PubMed]

40. Knight, A.; Shakeshaft, A.P.; Havard, A.; Maple, M.; Foley, C.; Shakeshaft, B. The quality and effectiveness of interventions that target multiple risk factors among young people: A systematic review. Aust. N. Z. J. Public Health 2017, 41, 54-60. [CrossRef] [PubMed]

41. Drummond, M.; Sculpher, M.J.; Claxton, K.; Stoddart, G.L.; Torrance, G.W. Methods for the Economic Evaluation of Health Care Programmes, 4th ed.; Oxford University Press: Oxford, UK, 2015.

42. Edmunds, K.; Wall, L.; Brown, S.; Searles, A.; Shakeshaft, A.P.; Doran, C.M. Exploring Community-Based Options for Reducing Youth Crime. Int. J. Environ. Res. Public Health 2021, 18, 5097. [CrossRef] [PubMed]

43. Knight, A.; Havard, A.; Shakeshaft, A.P.; Maple, M.; Snijder, M.; Shakeshaft, B. The feasibility of embedding data collection into the routine service delivery of a multi-component program for high-risk young people. Int. J. Environ. Res. Public Health 2017, 14, 208. [CrossRef] [PubMed]

44. Knight, A.; Maple, M.; Shakeshaft, A.P.; Shakehsaft, B.; Pearce, T. Improving the evidence base for services working with youth at-risk of involvement in the criminal justice system: Developing a standardised program approach. Health Justice 2018, 6, 8. [CrossRef] [PubMed]

45. Shakeshaft, A.; Doran, C.M.; Petrie, D.P.; Breen, C.; Havard, A.; Abudeen, A.; Harwood, E.; Clifford, A.; D'este, C.; Gilmour, S.; et al. The effect of community-action in reducing risky alcohol consumption and harm: A cluster randomised controlled trial. PLoS Med. 2014, 11, e1001617. [CrossRef] [PubMed]

46. Vissers, L.; Houwing, S.; Wegman, F. Recording of alcohol in official crash statistics: Underreporting and procedures to improve statistics. J. Australas. Coll. Road Saf. 2018, 29, 15-22.

47. Sims, S.; Preen, D.; Pereira, G.; Fatovich, D.; Livingston, M.; O’Donnell, M. Alcohol-related harm in emergency departments: Linking to subsequent hospitalizations to quantify under-reporting of presentations. Addiction 2021, 116, 1371-1380. [CrossRef] [PubMed] 